\title{
Vicente Castellano y su participación en los renovadores grupos: Los Siete y Parpalló
}

José Manuel Sánchez de Toro Universidad Politécnica de Valencia

RESUMEN:

Este artículo estudia la aportación del artista Vicente Castellano Giner (1927-2014) a la renovación de la pintura en los años cincuenta. En él se analizan los primeros años de su trayectoria desde su formación académica en la Escuela de Bellas Artes San Carlos de Valencia y su participación en dos de los grupos más importantes para la renovación artistica valenciana. El grupo Los Siete (1950-1954) y el grupo Parpalló (19561958). Donde presentó algunas de las propuestas más vanguardistas desarrolladas durante su estancia en París.

\section{PALABRAS CLAVE:}

Grabado/pintura/abstracción/Los Siete/Parpalló

\section{ABSTRACT:}

This article examines the contribution of the artist Vicente Castellano Giner (1927-2014) to the renewal painting of the fifties. It analyzes the early years of his career starting with his academic training at the Escuela de Bellas Artes San Carlos in Valencia, his work until the founding of the group Los Siete (1950-1954), and his attachment years later to the Parpalló group (1956-1958), where he presented some of the most innovative proposals developed during his stay in Paris.

\section{KEY WORDS:}

Engraving/painting/abstraction/Los Siete/Parpalló 
Vicente Castellano Giner nació el 13 de junio de 1927 en la calle Quart de la ciudad de Valencia. Los años de su educación coinciden con lo que históricamente se ha conocido como Restauración borbónica. El país sufría grandes convulsiones políticas, y se encontraba subyugado a la dictadura del general Miguel Primo de Rivera. Con la muerte de éste en 1930 el General Dámaso Berenguer se hace cargo del gobierno mientras se acrecienta el descrédito por la monarquía y especialmente por Alfonso XIII que era considerado cómplice del golpe de estado de Primo de Rivera. ${ }^{1}$ Toda esta situación produjo la caída del rey que voluntariamente tras las elecciones municipales de 1931, (consideradas como un plebiscito entre monarquía y república) le llevaron a exiliarse, allanando así la llegada de la II República Española que se proclamó el 14 de abril de 1931, cuando Vicente solamente tenía 4 años de edad. Con la llegada de la II República Española el panorama cultural español tornó a ser más cálido. Desde el primer momento el gobierno, apostó decididamente por los libros, las obras de teatro, el arte, en definitiva por la divulgación de la cultura en el pueblo español que era mayoritariamente analfabeto. ${ }^{2}$

Pero por muy fructífero que pudiese llegar a ser este período, la brevedad de su existencia impidió que la formación académica de Castellano se enmarcase en estos años, ya que en 1936 cuando Castellano apenas tenía 9 años de edad estalló la Guerra Civil Española, quedando el país paralizado durante el período que duró la contienda. Valencia, aun siendo una ciudad de retaguardia, vivió dramáticos episodios que focalizaron las preocupaciones del pueblo en el conflicto. ${ }^{3}$ Esta situación rompió las conexiones culturales y artísticas que había con la vanguardia europea, y únicamente fue reseñable en estos años la producción de cine y fotografía de carácter documental. No fue hasta después de la guerra, cuando empezó a estabilizarse la situación, y se estableció el nuevo régimen. Ya

FERNANDEZ LÓPEZ, Justo. "La dictablanda del General Berenguer" en http://hispanoteca.eu/Landeskunde-Spanien/Historia/La\%20dictablanda\%20del\%20 general\%20Berenguer.htm (consultado 1/02/2017).

2 MORÁN, Carmen. "Las enseñanzas de la Republica", El País, Madrid, 17 abril 2006, http://elpais.com/diario/2006/04/17/educacion/1145224801_850215.html (consultado 1/02/2017).

3 LLORENS CASTILLO, Carlos. La guerra en Valencia y en el frente de Teruel. (Ed) Fernando Torres, Valencia, 1978.

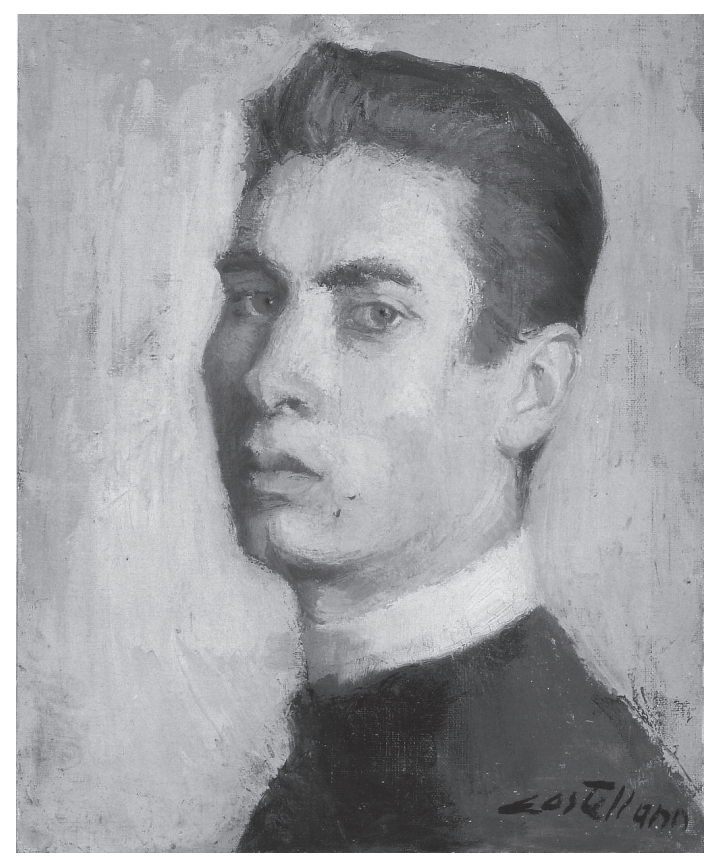

Figura 1: Vicente Castellano, Autorretrato, Óleo sobre lienzo, 1947/48, 41 x 33 cms.

en el año 1941, el joven Castellano fue matriculado en la Escuela de Artes y Oficios Artísticos y posteriormente ingresó en la Escuela Superior de Bellas Artes San Carlos de Valencia. Durante estos años destacó especialmente por su trabajo en pintura, dibujo y grabado, obteniendo el premio Roig ${ }^{4}$ por su trayectoria académica.

A lo largo de su período académico Castellano contó con maestros de la talla de Salvador Tuset o Enrique Ginesta del cual aprendió las convenciones de representación gráfica en las clases de perspectiva. Ginesta, al igual que otros muchos artistas y profesores, poseía un gran arraigo a la escuela sorollista y contrastaba fuertemente con el carácter rupturista de muchos de sus alumnos de estas generaciones. ${ }^{5}$ En este ambiente universitario, surge en 1946 el grupo Z, formado en su mayor parte por estudiantes de arte como: Jacinta Gil, Carme Pérez, Manuel Benet, Custodi Marco, Frederic Montañana, Josep Vento, Manuel Gil, y Ricard Zamorano, pero además de estos artistas que fueron miembros fundadores, colaboraron con el grupo de forma más o menos regular, otros

\footnotetext{
CASTELLANO GINER, Vicente. Amanecer, (Tesina de licenciatura), Inédita, Universidad Politécnica de Valencia, Valencia, 1982.

5 CASTELLANO GINER, Vicente. Encuentros con Vicente Castellano [DVD], Inédito, Valencia, octubre 2012.
} 
muchos, entre los que estaban Eusebio Sempere o el propio hermano de Vicente, Carmelo Castellano. ${ }^{6}$

En los cuatro años de existencia que estuvieron activos -en su mayor parte en la ciudad de Valencia- el grupo intentó revitalizar el arte de vanguardia y las nuevas corrientes estéticas contemporáneas. En un primer momento sus exposiciones comenzaron en la librearía Faus y posteriormente en la Sala Abad, desarrollando como afirma Juan Portolés "una revisión y una puesta a punto para la búsqueda estética verdaderamente encomiable", que perduró hasta la división del grupo y su posterior disolución en 1950 debido en parte a la muerte de Vicente Abad que venía realizando una importantísima labor de mecenazgo.

La idea renovadora que pretendían quedó en muchas ocasiones en un manifiesto de intenciones, sin llegar a constituir una efectiva renovación plástica, pero sin duda, habían reavivado la inquietud de encontrar nuevas expresiones plásticas. Este interés no surgió únicamente en Valencia, sino que en otros muchos lugares de la geografía nacional, surgieron también diferentes grupos de artistas que ejercieron presión contra el orden pictórico imperante, es el caso de "Los Indalianos" en Almería, "Dau al set" en Barcelona, el "Grupo Picasso" en Málaga o "Los Siete" en Valencia como herederos directos del "Grupo Z".

\section{Castellano en el Grupo Los Siete (1950 - 1954)}

Con la misma turbación de "Z", nace en 1949 el grupo "Los Siete", que aunque fundado antes de la disolución del grupo "Z" acaba recogiendo el testigo de su labor innovadora. Sus fundadores eran también jóvenes pintores, estudiantes de tercer curso de la Escuela de Bellas Artes San Carlos de Valencia, que una tarde al salir de una de sus clases fueron a una tasca donde charlaron de pintores como Goya, Dalí, Picasso, Daniel Sabater o Emilio Sala. Al final de la conversación surgió la idea asociativa para poder enfrentarse mejor a los problemas que dificultan las trayectorias de los artistas noveles. La intención era crear un clima pro-

$6 \quad$ PATUEL CHUST, Pascual. "El grupo Z i los siete en la pintura valenciana dels anys quarenta”, L' Espill, $n^{\circ}$. 29, Valencia, 1991.

7 PORTOLÉS, Juan. "La actual pintura española mediterráneo - levantina", Inquietud Artística, n 15, Vich, julio 1959, pág. 1 a 3 .

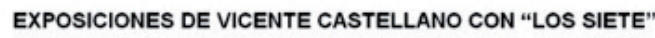

\begin{tabular}{|c|c|c|}
\hline año & mes & lugar \\
\hline 1950 & enero/febrero & Sala Colón 38 \\
\hline 1950 & abril & Sala Colón 38 \\
\hline 1950 & octubre & Sala Colón 38 \\
\hline 1950 & noviembre & Sala Colón 38 \\
\hline 1950 & diciembre & Sala Colón 38 \\
\hline 1951 & marzo & Sala Colón 38 \\
\hline 1953 & febrero & Sala Colón 38 \\
\hline 1953 & abril/mayo & Sala Braulio \\
\hline 1953 & octubre & Sala Braulio \\
\hline 1953 & noviembre & Sala Braulio \\
\hline 1953 & diciembre & Sala Braulio \\
\hline 1954 & mayo & Sala Braulio \\
\hline
\end{tabular}

Figura 2: Participación de Vicente Castellano en las exposiciones del grupo Los Siete.

picio para desarrollar su actividad. Esa misma noche, antes de constituir formalmente el grupo se acordó el nombre de "Los Siete", obedeciendo al número de fundadores que compusieron en un primer momento el colectivo; estos fueron: Vicent Fillol Roig, Joan Genovés, Vicent Gómez García, Joan Llorens Riera, Josep Masià Sellés, Ricardo Hueso y Vicente Castellano.

El grupo empezó su andadura con gran actividad organizando reuniones cada viernes en el café "La Lonja", donde debatirian sobre los temas de actualidad y compartirian opiniones. Las reuniones serían muy concurridas, hasta tal punto que sería imposible mantener un único tema de conversación, formándose así grupos con diferentes charlas mientras tomaban un café y fumaban. Pero el grupo era consciente de la necesidad de encontrar un lugar no solamente donde charlar, sino también donde trabajar, y tuvieron la suerte, de que al poco tiempo de conformarse encontraron un local en la calle Quart donde desarrollaron la actividad artística. ${ }^{8}$

Sus aspiraciones no pretendían un fin lucrativo, sino por el contrario, superarse como artistas en un ambiente adverso, hacer de sus tertulias instrumentos útiles para la cultura, para lo cual invitaban a pintores y artistas consagrados, también mediante la organización de conferencias. Aunque el grupo no llegó a tener nunca unos estatutos por medio de los cuales se rigieron, Los Siete tenían bastante claro cuál era la naturaleza y la trayectoria que debían de seguir, como lo ponen de manifiesto en una entrevista de 1950 donde afirman que nadie dirige el grupo y que todos tienen voz y voto. ${ }^{9} \mathrm{Du}-$

\footnotetext{
CASTELLANO GINER, Vicente. Encuentros... Opus cit.

9 VALENZUELA. "Charlando con "Los Siete», grupo de pintores jóvenes y entusiastas", Jornada, Valencia, 31 enero 1950, pág. 3.
} 


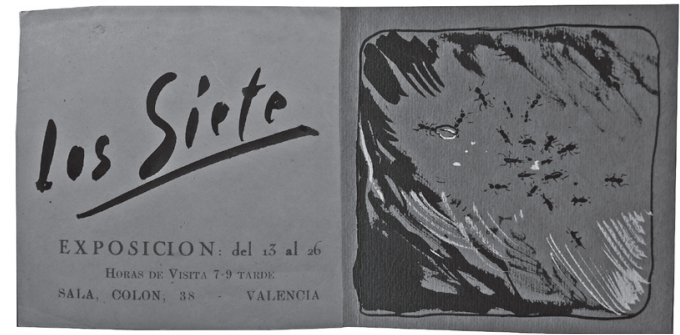

Figura 3: Catálogo de exposición Los Siete, 13 - 26 octubre, Sala Colón, Valencia, 1950.

rante su período de vigencia, las exposiciones colectivas fueron su principal actividad, pero no obstante, también organizaron conciertos, recitales y colaboraron con otros artistas y grupos de todos los ámbitos del arte.

El trabajo pictórico que llevaron paralelamente cada uno de los artistas en el taller de la calle Quart, era expuesto al público -previa selección de las obras por cada uno de los autores- en las diferentes exposiciones que se celebraron periódicamente en Valencia, generalmente en un establecimiento comercial de la calle Colón número 38, cedido desinteresadamente y acondicionado para tal fin con motivo de cada una de las exposiciones. La primera muestra se inauguró el 26 de enero de 1950, teniendo una duración de trece días, dicho acontecimiento fue recogido en las notas culturales de la prensa, que anunciaban clamorosamente la inauguración de la exposición. ${ }^{10}$

En esta primera exposición -en la cual sólo pudieron exponer seis de los siete fundadores-, se colgaron un total de once obras y obtuvieron comentarios elogiosos por parte de la crítica, así López-Chavarri escribió: "La impresión total, repitámoslo, es de grata novedad; se trata de jóvenes, pero que se ve han trabajado disfrutando en la labor, y han sabido evitar la técnica facilona, para mejor expresar lo íntimo de su emoción”. Y concretamente en referencia a la obra Niños de Castellano continuó diciendo: "Tiene empastes de verdadera sencillez acertada. Muy sentido de color y de intención el "niño de la botella»".

En abril de este mismo año 1950, Los Siete celebraron su segunda exposición volviendo a

10 ANÓNIMO. "Próxima exposición de "Los Siete»", Levante, Valencia, 25 enero 1950, pág. 4.

1 LÓPEZ-CHAVARRI ANDÚJAR, Eduardo. "Exposición de "Los Siete"”, Las Provincias, Valencia, 1 febrero 1950, pág. 5 . exponer en su local de Colón 38. En este caso Castellano presentó un total de tres obras, destacando entre ellas el óleo Autorretrato. En esta segunda cita los artistas expusieron un mayor número de obras, que fue acompañado también a juicio de Garín por un aumento de la calidad, en lo exhibido:

Hay progreso evidente en la obra expuesta de Los Siete, cada vez más digna de aliento y de apoyo práctico... Un conjunto, en verdad este de Los Siete, prometedor y entre sus diversos miembros complementario sobre todo por la amplia y libre concepción estética que le orienta y la aplicación entusiasta que le inspira y se advierte en toda su obra. ${ }^{12}$

La evolución del grupo es palpable por los espectadores y así lo recogen en sus impresiones, no obstante el grupo trabajó con tesón para desarrollar el proyecto común al máximo, cuidando hasta los detalles más sutiles; como la factura manual de los catálogos, que ellos mismos confeccionaban en la sala de exposiciones. Es el caso del catálogo de la muestra celebrada en octubre de 1950, donde se vuelve a presentar una nutrida representación de sus trabajos y entre ellos 3 obras de Castellano que demostraron la versatilidad del artista: Retrato, un apunte titulado Estudio y su obra más alabada en esta muestra, titulada Color, "un pastel espontáneo en el que muestra sus condiciones de pintor jugoso y constructivo". ${ }^{13} \mathrm{La}$ ilusión era la reseña común en todas las noticias de prensa que se publicaban con motivo de las exposiciones del grupo, tal fue el entusiasmo, que desarrollaron una efervescente actividad artística. En ocasiones llegaron a celebrar una muestra por mes y se solían colgar tres obras por artista, como vemos en la cuarta exposición, donde Castellano presentó Marionetas de la fiesta, Pintura y Ensimismada. Un mes después se volvieron a convocar en su ya habitual sala de Colón 38, para presentar una serie de trabajos bajo la temática navideña. Sería la primera exposición que unificó el contenido de las 150 obras que allí presentaron. Sin embargo y aunque el colorido era la nota predominante, técnicamente se pudieron ver distintas obras, desde realistas hasta más vanguardistas, con diferentes estéticas y estilos, elaboradas con lápices, acuarelas, collages, o tintas. Todas las ilustraciones a modo de "christmas" se colgaron

\footnotetext{
12 GARÍN, Felipe. "Exposición de "Los Siete»", Levante, Valencia, 30 abril 1950, pág. 3.

13 S. R. "Exposición de "Los Siete»", Levante, Valencia, 22
} octubre 1950, pág. 6 . 
en una sala totalmente ambientada para la ocasión con guirnaldas, luces y motivos navideños. La exposición, como atestigua la prensa fue un éxito, y prueba de ello fue la venta de muchos de los tarjetones allí colgados. "Sin duda ha sido un acierto dedicar varias fechas de su actividad expositora a esta pintoresca expresión artística, como prueba la excelente inmejorable acogida que ha merecido del público que la ha visitado, adquiriendo casi todo lo expuesto". ${ }^{14}$

La regularidad en los períodos que trascurrían entre exposición y exposición, dependió de muchos factores, entre ellos, del ritmo de trabajo y la disponibilidad de cada uno de los miembros del grupo. Igualmente era también variable el tiempo de exposición de cada muestra, desde períodos superiores a dos semanas, hasta más cortos, como los de la exposición de marzo de 1951, donde la muestra solamente fue visitable durante cinco días. En ella se expusieron un total de veinte obras entre las que se encontraba la composición Hermandad de Castellano. A partir de esta muestra de marzo de 1951 el grupo perdió algo de fuerza en lo que se refiere a su frecuencia expositiva, en parte debido a la movilidad de los artistas, por la concesión de diferentes becas y ayudas para complementar y finalizar estudios en el extranjero. Por ello, transcurrido un tiempo sin actividad se volvieron a reunir en febrero de 1953 para exponer de nuevo y presentar a Ángeles Ballester que entró a formar parte del grupo. ${ }^{15}$

Para dicha exposición en la que ya participó Ballester los artistas realizaron un total de trescientos catálogos impresos, en cuyas portadas dejaron un gran espacio en blanco, para ser ilustradas a mano con apuntes de color realizados por ellos mismos de forma anónima. La muestra reafirmó la vivacidad y solidez del grupo, entre ellas la de Castellano del que Garín dijo: "Vicente Castellano sobre todo en su "Claro-oscuro" reitera las notas de solidez y penetrante expresión que venía definiéndole”. ${ }^{16}$ Efectivamente estas palabras no hacían nada más que constatar una realidad, tal y como relata uno de sus compañeros a Carlos Sentí

14 GARÍN, Felipe. "Exposición de tarjetas de Navidad organizada por "Los siete»", Levante, Valencia, 24 diciembre 1950, pág. 5 .

15 LÓPEZ-CHAVARRI ANDÚJAR, Eduardo. "Exposición de "Los Siete»", Las Provincias, Valencia, 1 febrero 1953, pág. 14.

16 GARÍN, Felipe. "Exposiciones "Los Siete»", Jornada, Valencia, 6 febrero 1953, pág. 11

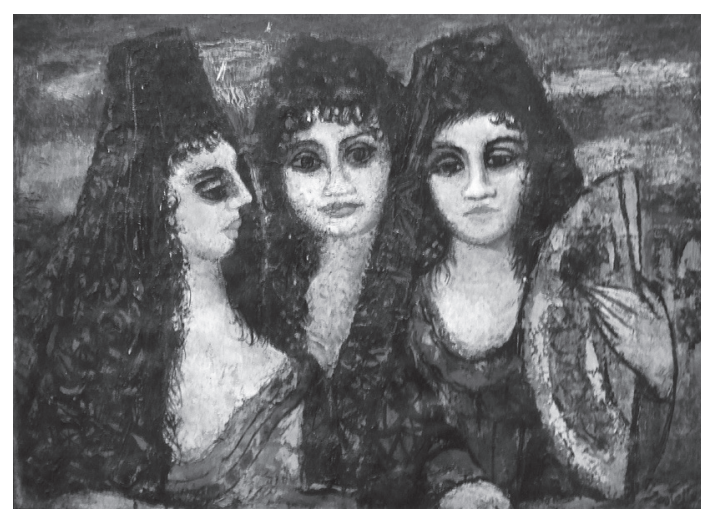

Figura 4: Vicente Castellano, Las Manolas, Óleo sobre lienzo, 1954, $52 \times 78 \mathrm{cms}$.

Esteve, en una entrevista concedida al cierre de la exposición: "Vicente Castellano tiene dos medallas de oro, máximo galardón en las exposiciones del S. E. U., excelente grabador, es actualmente pensionado de la diputación; ahora se nos va a París". ${ }^{17}$ La trayectoria meritoria como estudiante avalaba su quehacer como pintor y le hizo merecedor de una de las pensiones que condecía la Diputación de Valencia.

La siguiente exposición que se celebró dejó su ya habitual "Sala Los Siete" (como se renombró al pequeño local de la calle Colón), para trasladarse a la Sala Braulio donde ganaron en comodidad y amplitud, y así fue apreciado por los espectadores que después escribieron: "El grupo "Los Siete»... presentó en la Sala Braulio la más cuajada de sus exposiciones, no se le debe regatear por ella ni los alientos, que ampliamente merece, ni tampoco las alabanzas de las que ha sabido hacerse acreedor. Sencillamente "Los Siete», acaban de iniciar una nueva etapa en el camino que recorren cada vez con paso más firme, seguro y decidido". ${ }^{18}$

Sus integrantes mantuvieron en todo momento una trayectoria heterogénea, que no constituyó una estética común y nunca tuvo unas directrices previamente marcadas. Los propios miembros declararon "Nuestras diferencias son algo más que matices. No nos encontramos unidos por la misma escuela. Cada uno tiene estilo distinto. Sólo estamos vinculados por una misma ambición y unos mismos

17 SENTÍ ESTEVE, Carlos. "Una entrevista a siete voces. Un inquieto y brillante grupo de pintores jóvenes valencianos”, Levante, Valencia, 8 febrero 1953, pág. 5.

18 OMBUENA, José. "Exposición de «Los Siete» en la Sala Braulio", Levante, Valencia, 30 abril 1953, pág. 6. 
deseos". ${ }^{19}$ Esta ambición colectiva tenía como objetivo llegar a nuevas soluciones plásticas, de este modo, cada uno entendía necesario un trayecto diferente para abrir nuevos imaginarios.

El historiador Pascual Patuel, ha analizado la trayectoria del grupo y ha constatado los diferentes derroteros artísticos de cada uno de sus miembros. Respecto a Castellano destaca de sus primeras obras con Los Siete, la influencia de artistas como Vázquez Díaz o de Gutiérrez Solana, en cuadros de pequeños formatos en tonos rojos y marrones. ${ }^{20}$

Las obras que Castellano realiza durante estos años en su etapa formativa evidencian un constante interés por la densidad de la pintura y poseen como afirma Román de la Calle "una sólida construcción figurativa, un fuerte aire de familia", ${ }^{21}$ hemos de tener en cuenta que durante su infancia, el artista siempre tuvo presente la obra de su padre, el pintor Carmelo Castellano Ibáñez, cuyas pinturas religiosas iban destinadas al ornato de numerosas iglesias valencianas. Sin embargo los personajes que aparecen en los lienzos de Vicente Castellano se alejan del aspecto piadoso y poseen matices mucho más caricaturescos, destacando también por la robustez de sus formas y por un premeditado hieratismo.

En general, en cada convocatoria el grupo dejaba patente la huella de su evolución. Sus miembros iban descubriendo caminos, asentado sus técnicas y enriqueciéndolas, a la vez que alimentándose mutuamente con nuevas experiencias. Sus intenciones eran palpadas, llegaban al público, y así quedaron recogidas: "Esta moderna estética de la emoción es la que se ve en estos trabajos, en donde se acude a una técnica por ella misma, sino por la espiritualidad que representa. Cuando en este punto se llega a la liberación, cuando no se es esclavo del «hacer», se está en constante camino de perfección, y ésta es otra de las bellas cualidades que ofre-

19 VALENZUELA. "Charlando con "Los Siete», grupo de pintores jóvenes y entusiastas”, Jornada, Valencia, 31 enero 1950, pág. 3.

20 PATUEL CHUST, Pascual. “El grupo Z i los siete... Opus. cit.

21 DE LA CALLE, Román: "Vicente Castellano. Del camino a la estructura”, en cat. exp. Vicente Castellano. Pintures. Exposició Antológica, Consorci de Museus de la Comunitat Valenciana y Fundación Chirivella-Soriano, Valencia, 7 mayo - 5 septiembre 2010, pág. 27.

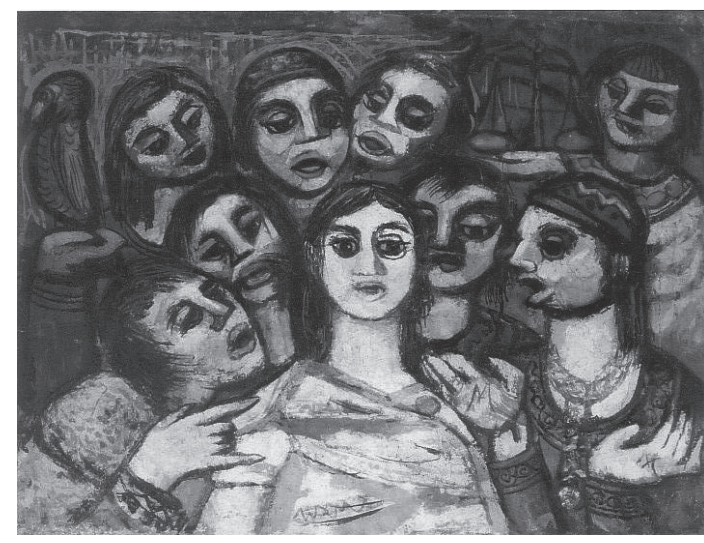

Figura 5: Vicente Castellano, Jesús en el Templo, Óleo sobre lienzo, $1953,54 \times 73 \mathrm{cms}$.

cen "Los Siete», un anhelo de superación propio de los espíritus propiamente artistas".22

Esta pintura con "trasfondo liberador" iba más allá de lo meramente pictórico, como es el caso de la exposición de octubre de 1953, donde inauguraron el curso presentando los trabajos veraniegos acompañados de música. Concretamente de un arpa que vibró de la mano de la profesora y solista de la orquesta municipal María Luisa Jiménez, siendo antes precedida por una conferencia de arte musical valenciano, que pronunció el compositor Agustín Alamán, fundador y director en aquel momento de la Coral Polifónica de Valencia. ${ }^{23}$

Además la conciencia vanguardista de Los Siete necesitaba nutrirse constantemente en muchos otros aspectos, también en el meramente técnico. Por ello, y a pesar de sus limitados recursos, se esforzaban en confrontar diferentes experiencias pictóricas. Así lo hicieron en noviembre de este mismo año cuando volvieron a reunirse en la Sala Braulio junto a un grupo de jóvenes pintores madrileños entre los que se encontraban: Ángel Duarte, Adela Parrondo, Julio Álvarez y Enrique Calvo. Este ejercicio que los artistas noveles madrileños hicieron desplazándose a Valencia, fue realizado a la inversa por Vicente Castellano y Joan Genovés, cuando este mismo año llevaron sus obras a la Exposición Nacional del Frente de Juventudes celebrada en Madrid, en la que fueron afortunadamente pre-

22 LÓPEZ-CHAVARRI ANDÚJAR, Eduardo. “"Los Siete» en la Sala Braulio”, Las Provincias, Valencia, 22 octubre 1953, pág. 16.

23 LÓPEZ-CHAVARRI ANDÚJAR, Eduardo. "Conferencia y concierto de arpa en la Sala Braulio”, Las Provincias, Valencia, 28 octubre 1953, pág. 14. 
miados, en el caso de Castellano por sus grabados, entre los que destacaba Interior de $\mathrm{la} \mathrm{Ca}$ tedral de Valencia. ${ }^{24}$ Es evidente que si el compartir experiencias en cualquiera de los ámbitos de la vida es algo verdaderamente útil, mucho más necesario resulta en lo referente a cualquier práctica artística, donde esta comunión de experiencias es sumamente constructiva.

A finales de 1953 con la llegada de las fiestas navideñas el grupo decidió repetir la fructuosa idea que tuvieron en 1950 con la organización de una exposición de dibujos, pinturas y tarjetas de navidad. Es entendible que la sociedad valenciana de los años cincuenta recibiera esta muestra con agrado, como una iniciativa entrañable, frente a otras muestras que pudiesen ser menos entendidas por presentar obras de carácter más rompedor e innovador que no llegasen a ser descodificadas por el público. En esta muestra previa a los días de Navidad, los artistas presentaron estampas con motivos tradicionales, mayormente ilustraciones relativas al nacimiento de Cristo, como por ejemplo sendas obras de Pomr y Castellano que presentaron diferentes visiones de la Sagrada Familia. ${ }^{25}$ Sería la penúltima exposición del grupo ya que con la llegada del nuevo año vería su disolución, celebrando el último encuentro expositivo en mayo de 1954.

Aunque los miembros del grupo eran conscientes de la desaceleración progresiva de sus actividades, en parte debido a los desplazamientos de los artistas, propiciados por el disfrute de becas y pensiones, éstos nunca serían conscientes de la que iba a ser su última exposición, ya que la muestra no supuso una despedida formal, incluso podemos decir que no entraba en sus intenciones la disolución del colectivo, ya que los miembros que no podían participar eran sustituidos por otros nuevos artistas, como fue el caso de la baja causada por Fillol Roig cuyo lugar ocuparía el alicantino Eusebio Sempere. ${ }^{26}$

En esta última aparición pública de Los Siete, Vicente Castellano presentó las obras: Jesús en el templo, interpretaciones como Canal o Carrou-

24 LÓPEZ-CHAVARRI ANDÚJAR, Eduardo. "«Los Siete» presentan a los jóvenes pintores madrileños en la Sala Braulio", Las Provincias, Valencia, 19 noviembre 1953, pág. 4.

25 LÓPEZ-CHAVARRI ANDÚJAR, Eduardo. "Pintura y música”, Las Provincias, Valencia, 16 diciembre 1953, pág. 16.

26 HACE. “"Los Siete» en la Sala Braulio”, Jornada, Valencia, 12 mayo 1954, pág. 8. sel y sus curiosas Monoestampaciones. ${ }^{27}$ Obras elaboradas con generosas capas de pintura, que el artista modela sobre la superficie del lienzo, cuyas figuras de grandes contrastes, presentan la rigidez y el frontalismo del arte románico. Un arte que había fascinado al artista años antes cuando realizó el camino de Santiago.

En este tiempo, Castellano concurre a la Pensión de Grabado convocada por la Diputación de Valencia en 1950 lo que le facilita estancias en otras ciudades españolas, donde a pesar del régimen se reconoce una cierta libertad artística, ya que curiosamente desde el propio gobierno se pide a los artistas que produzcan un arte de su tiempo. ${ }^{28}$ Una libertad que resultó claramente insuficiente y se verá teñida por los conceptos de españolidad y religiosidad del franquismo, clichés que Vicente Castellano transgredió finalmente en su voluntario "exilio" parisino.

\section{Castellano en el Grupo Parpalló (1956 - 1958)}

A principios del año 1956 aparecen en Madrid una serie de revueltas suscitadas por los colectivos universitarios que se rebelaron contra el régimen establecido. Estos hechos fueron conocidos como Sucesos de 1956 y acabaron con la destitución por parte del General Franco, del ministro de educación Joaquín Ruiz-Giménez. ${ }^{29}$

Estas revueltas eran producto de las inquietudes e inconformidades de los más jóvenes, y en mayor o menor medida se produjeron a lo largo de la década de los años sesenta y setenta. Eran momentos convulsos donde la castigada España que había permanecido en silencio durante tanto tiempo empezaba a reaccionar.

En el panorama artístico nacional empezaron a surgir colectivos y agrupaciones de artistas que aunaron esfuerzos con el fin de hacer frente al desierto cultural que existía en el país. Fue el caso de grupos como El Paso fundado en Madrid en febrero de 1957 o Equipo 57 fundado en París por artistas españoles en mayo de

27 LÓPEZ-CHAVARRI ANDÚJAR, Eduardo. “"Los Siete” en la Sala Braulio", Las Provincias, Valencia, 5 mayo 1954, pág. 7.

28 DÍAZ SÁNCHEZ, Julián. El triunfo del informalismo. La consideración de la pintura abstracta en la época de Franco, Metáforas del Movimiento Moderno, Madrid, 2000, pág. 23.

29 EIROA SAN FRANCISCO, Matilde. "España en el marco de las crisis mundiales de 1956”, Historia Actual Online, nº 10, Cádiz, 2006, pág. 135 a 136. 
este mismo año, o el Grupo Parpalló fundado algunos meses antes, en octubre de 1956, en la ciudad de Valencia. ${ }^{30}$

El surgimiento del grupo Parpalló se llevó a cabo al abrigo del Instituto Iberoamericano de Valencia que pretendía rescatar la actividad artística de la ciudad levantina, igualmente, para los jóvenes pintores y escultores suponía también una excelente plataforma para desarrollar sus obras, tal y como ya destaco el historiador del grupo Pablo Ramírez: "Para los artistas la oferta no podía ser más tentadora, una entidad acreditada en el ámbito de la cultura y políticamente libre de toda sospecha, se ponía a su disposición para facilitarles algo tan importante como la difusión de su trabajo. Se comprenderá entonces que la idea de formar parte de un colectivo artístico fuera aceptada prácticamente por unanimidad". 31

El grupo fue fundado el 23 de octubre de 1956 estando reunidos como integrantes fundadores, los pintores Manolo Gil, Jacinta Gil, Juan de Ribera Berenguer, Vicente Pastor Pla, Víctor Manuel Gimeno, Joaquín Michavila, Salvador Montesa, y los escultores Nassio Bayarri y José Esteve Edo, el médico Ramón Pérez Esteve, y el teórico y crítico Vicente Aguilera Cerni.

En la época de la fundación del Parpalló, Vicente Castellano ya residía en la capital francesa, por lo que no acudió a la reunión fundacional del grupo, siendo incorporado en un viaje posterior en noviembre de 1956; cuando regresó para inaugurar su exposición en el $\mathrm{Pa}-$ lacio de la Generalidad. Fue entonces cuando acudió al Ateneo Mercantil donde estaban reunidos los miembros del recién constituido grupo e ingresó junto con el escritor José Luis Aguirre.

Como queda patente y bien relata Pablo Ramírez la idea de permanecer al colectivo sería de gran interés a juzgar por las posteriores altas que causaron en el grupo en junio de este mismo año, los arquitectos Juan José Estellés y Roberto Soler Boix, el decorador José Martínez Peris y el pintor Salvador Soria y meses después en diciembre lo haría el pintor Monjalés y el periodista Juan Portolés.

30 PATUEL CHUST, Pascual. "El Grupo Parpalló (19561961)", Archivo de Arte Valenciano, año LXXI, Valencia, 1990, pág. 162 a 171.

31 RAMÍREZ PÉREZ, Pablo (comis.). Grupo Parpalló: 1956-1961 [cat. exp.], Palau dels Scala - Sala Parpalló, enero - febrero 1991, Diputación Provincial de Valencia, Valencia, 1991, pág. 21.
El primer documento público del grupo fue la I Carta abierta que se publicó en todos los diarios regionales el 1 de diciembre de 1957. Entre los firmantes de la misma podemos ver a Vicente Aguilera Cerni, José Luis Vila, Salvador Montesa, Vicente Pastor Pla, Ramón Pérez Esteve, Francisco Pérez Pizarro, Luis Prades Perona, Juan de Ribera Berenguer y Adrián Sancho Borja. Con ella pretendían hacer eco de sus intenciones en la sociedad, y así lo anuncian desde las primeras líneas del texto: "Varios pintores, escultores, escritores y aficionados, nos hemos agrupado bajo el nombre venerable del Parpalló (primer dato de una tradición cultural incesantemente renovada, una tradición creadora de constante vitalidad) para reunir esfuerzos y trabajos en los distintos sectores del arte a los que estamos vinculados". ${ }^{32}$

Además de manifestar la creación de un marco cultural propicio para el desarrollo de sus actividades, también intentaban una integración de todos los que deseaban la trascendencia de un nuevo arte, en este sentido añoraban la falta de una escuela propia valenciana, quizá no tanto por falta de talentos, sino por falta de una briosa iniciativa común, ya que ellos mismos reconocían que los artistas valencianos pasaban a formar parte de otras escuelas: "Haremos lo posible por reivindicar la mortecina vida artística valenciana. Sobre todo queremos acabar con esa injusta "conspiración del silencion, según la cual nuestros artistas van pasando a engrosar otras "escuelas" locales (concretamente las de Madrid y Barcelona), cuando debiera tener carta de naturaleza y reconocimiento nacional la "Escuela de Valencia». Así, hemos acogido jubilosamente la unión de castellonenses, alicantinos y valencianos, aunque alguno de nosotros resida actualmente fuera del antiguo reino".33

Referencia esta última, entre otros casos, al del propio Castellano que ya residía en París, pero aun así, participó de forma activa en las exposiciones y actividades del grupo. Esta situación, dificultó la consecución de una mayor unidad del colectivo tal y como algunos miembros siempre desearon. Es el caso de Aguilera Cerni que en más de una ocasión planteó la cuestión de la integración entre todos sus

\footnotetext{
32 GRUPO PARPALLÓ. "Carta abierta del "Grupo Parpalló»", Las Provincias, Valencia, 1 diciembre 1956, pág. 13.

33 Ídem.
} 


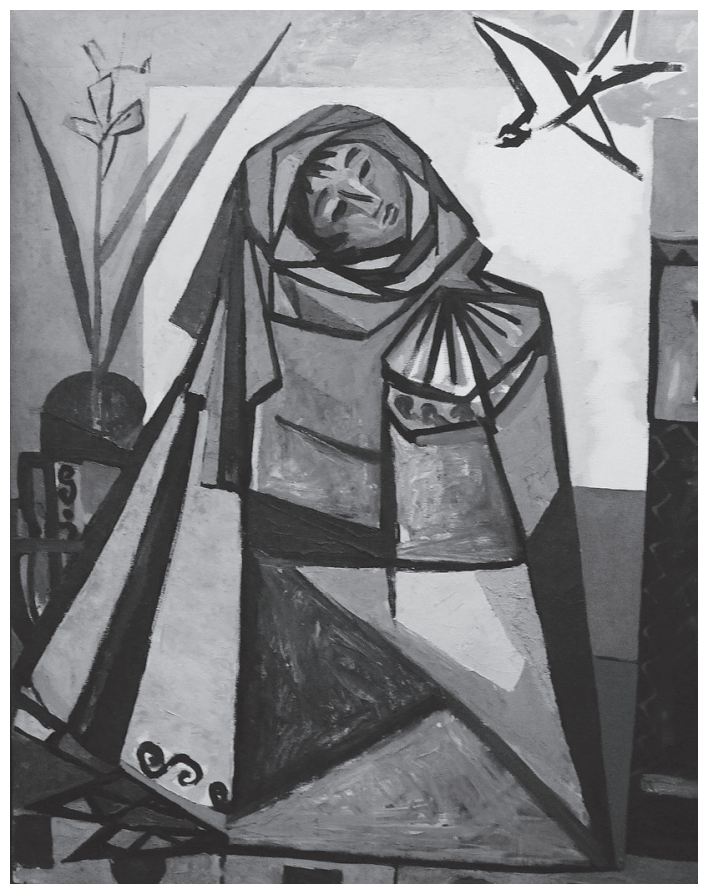

Figura 6: Vicente Castellano, La Anunciación, Óleo sobre lienzo, $1956,100 \times 81 \mathrm{cms}$

miembros. ${ }^{34}$ Aunque presumiblemente, ya en los comienzos, todos eran conscientes de la hetereogeneidad del colectivo.

Por otro lado, con la llegada de Vicente Castellano a la capital francesa su obra se diversifica y recibe influencias de la vanguardia clásica, principalmente del cubismo y el constructivismo. Sus composiciones cada vez más cuarteadas forman las figuras por medio de facetas o planos de color. Se produce una deriva hacia soluciones formales más sintéticas, donde lo meramente plástico empieza a cobrar fuerza expresiva en detrimento del anclaje que suponía la figuración. Los personajes de sus escenas, cada vez más simplificados, acaban configurando composiciones poligonales que progresivamente lo conducen hacia la abstracción geométrica.

En Valencia, la actividad inicial del grupo fue tan meteórica que el mismo día 1 de diciembre se publicó la I Carta abierta a la sociedad y se inauguró la primera exposición conjunta en el Ateneo Mercantil. La muestra contó con la

34 AGUILERA CERNI, Vicente. "Grupo Parpalló" en cat. exp. $4^{a}$ Exposición Grupo Parpalló. Homenaje a Manolo Gil, Sala Prado 14 - 25 enero 1958, Ateneo, Madrid, 1958. participación de los pintores Agustín Albalat, José Marcelo Beneditto, Amadeo Gabino, Juan Genovés, Jacinta Gil, Manuel Gil Pérez, Víctor Manuel Gimeno, Joaquín Michavila, Salvador Montesa, Vicente Pastor Pla, Francisco Pérez Pizarro, Juan de Ribera Berenguer y Vicente Castellano, y de los escultores Nassio Bayarri, José Esteve Edo y Amadeo Gabino. En su totalidad se exhibieron cuarenta y dos obras y entre ellas las piezas número seis, titulada Estructuras, la número siete titulada Collage, y la número ocho, también titulada Collage, presentadas las tres por Vicente Castellano.

A juzgar por la crítica de la exposición esta primera experiencia grupal no salió muy bien parada y se le achacaron entre otras cosas la de no ofrecer nada nuevo a lo que ya se había podido ver de estos artistas, no obstante se les tachó casi de "enfermos" cuando Rafael Alfaro escribió: "Una obsesión casi patológica con el modernismo en rabiosa competencia dentro del grupo" y paradójicamente después de reprochar la transgresión de los artistas, acaba defendiendo el cariz innovador que deben de tener los creadores, especialmente los noveles: "entendemos, que no sólo es lícito y aconsejable que los pintores jóvenes traten de romper los moldes de un academicismo a veces acartonado y arcaico para buscar honestamente un camino propio y centrar su propia personalidad." 35

Es evidente por sus palabras, que la innovación que el crítico estimaba que debían hacer los artistas, no iba en la dirección de lo que los propios artistas pretendían. Pero no todo queda ahí, la crítica hace particular alusión a determinados artistas como es el caso de Castellano, al que se refiere de la siguiente manera: "De este encasillamiento ya habría mucho que hablar, porque no sabemos qué tienen que ver con la pintura, por ejemplo los "collages» de Castellano, ni esos muestrarios de chatarrero que presenta Montesa”. Con total firmeza habla de las obras más transgresoras y continúa arremetiendo contra los pintores más atrevidos: "Parece trascender más bien una casi absoluta insinceridad, con la que más que inducir error al visitante, parecen tratar de engañarse a sí mismos.... Cómo puede alcanzar belleza plástica alguna, uno de los "collages" de Castellano...." 36

\footnotetext{
35 ALFARO, Rafael. “"El Parpalló» en el Ateneo Mercantil”, Jornada, Valencia, 4 diciembre 1956, pág. 4.
} 36 Ídem. 
Sobre este cuestionamiento que hace de las obras, hoy poco se puede decir. Quizá en aquella España en blanco y negro de 1956 se pudo establecer algún discurso al respecto, pero el tiempo y la historia del arte se encargaron de acreditar estas técnicas plásticas, que acabaron entrando en los circuitos del arte español. Hoy sería totalmente descabellado poner en duda la legitimidad de determinadas prácticas artísticas como el «collage».

Por otro lado, Alfaro también desacredita la concomitancia que los artistas tienen por la formación de una escuela artística propia en Valencia, una "Escuela de Valencia», que según él: "Ni existe en realidad, ni se la echa de menos en la creación artística de los pintores y escultores valencianos". ${ }^{37}$ Y quizá no existiese ninguna escuela valenciana como él afırma, pero no por ello sería del todo ortodoxo dejar de alentar esta idea a quienes difirieron en su percepción de la realidad artística valenciana de los años cincuenta. No obstante, es de reconocida justicia decir que no todas sus palabras fueron ofensivas y tuvo elogios en su escrito para los artistas de la sección de escultura.

Sin embargo desde una perspectiva interna, a través de la visión de Manolo Gil, miembro del grupo, podemos constatar cómo los artistas más duramente tratados por esta crítica de $\mathrm{Al}$ faro fueron los que en mayor o menor medida se alejaban de la figuración. Dice Gil al respecto de esta primera exposición: "Entonces viene la sorpresa Montesa y Castellano presentan cosas abstractas" ${ }^{38}$. La abstracción sería una línea de creación muy secundada, una dirección estética que Castellano abanderó y que después fue seguida por otros miembros del grupo como leemos: "El Grupo Parpalló como hemos visto ha adquirido mucha importancia por el encuentro inesperado por todos de un sentido investigador compartido por la mayoría del grupo. En esta mayoría estamos: Montesa, Pastor, Castellano, Marcelo, Jacinta, Soria y yo. El resto todavía no se decide a abandonar los moldes en desuso y trabajar con ahínco en la búsqueda de un nuevo molde de expresión." ${ }^{39}$

Esto no hace nada más que corroborar el eclecticismo existente en el grupo, que ellos

37 Ídem.

38 GIL, Manolo citado por: RAMÍREZ PÉREZ, Pablo (comis.). Grupo Parpalló: 1956-1961 50é aniversari [cat. exp.], Consorci de Museus de la Comunitat Valenciana, Generalitat Valenciana, Valencia, 2006, pág. 21.

39 Ídem.

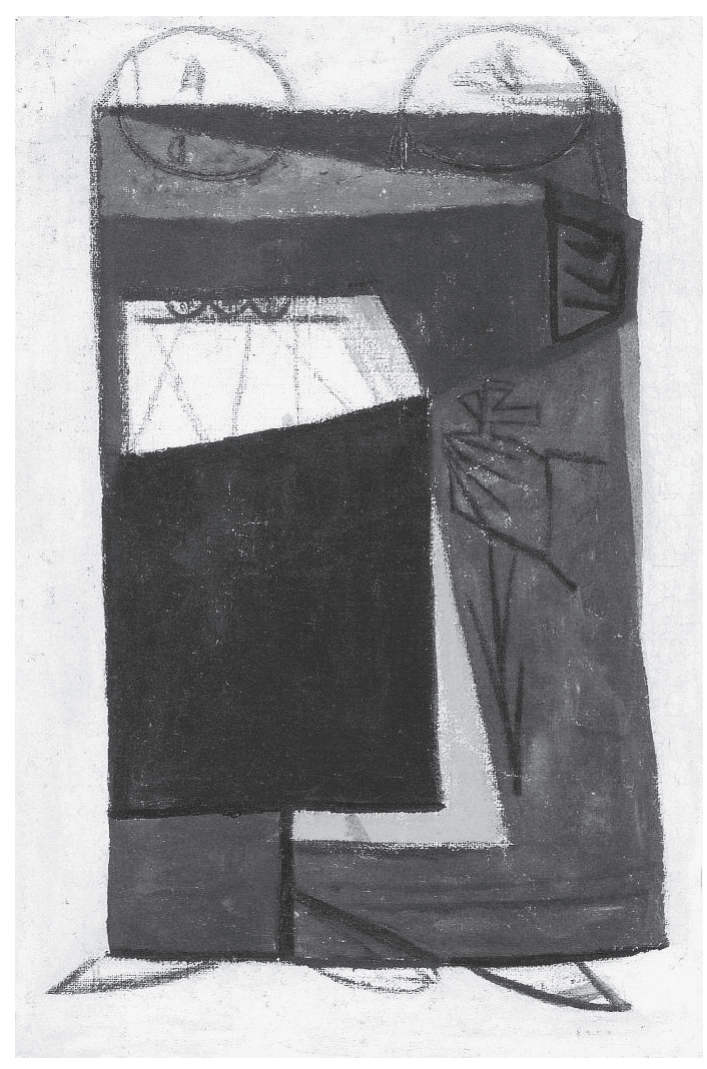

Figura 7: Vicente Castellano, La Visitación, Óleo sobre lienzo, 1956, $81 \times 54 \mathrm{cms}$.

mismos ya anunciaron en su I Carta abierta. Pero aun así dentro de este variopinto escenario, la pretensión de buscar nuevos modelos estéticos rondaba -en mayor o menor medida- por la cabeza de todos los artistas, aunque evidentemente, no todos tuvieron la misma determinación en ejecutar la ruptura con los cánones pasados. Romper estos modelos suponía la renuncia a una figuración académica que ellos técnicamente dominaban y que gozaba popularmente de reconocimiento, para adentrarse en un incierto camino, que entre otras cosas requería, una total confianza en su labor como artista, que sería fundamental para hacer cara al maremágnum ideológico imperante y a la siempre temida afrenta social.

Fueron los artistas con mayor arrojo, los que fehacientemente no sentían como propio aquello que hacían, y no quisieron resignarse a repetir lo aprendido, los que asumieron los riesgos de buscar un derrotero artístico que les permitiese canalizar sus amplias inquietudes en el campo de la abstracción, independientemente de cosechar resultados plásticos, que no supie- 
sen ser descodificados por la sociedad o correctamente interpretados, y además expuestos a infundadas y superficiales críticas producto del más absoluto desconocimiento. Por ello, cabe destacar en el grupo la labor de artistas como Castellano que supieron desligarse de cualquier anclaje pasado, eso sí, dejándolo como escribió Aguilera Cerni “sólidamente aprendido". ${ }^{40}$ Transgresión que le valió en alguna ocasión como ésta, palabras de la crítica francamente poco alentadoras para un artista.

En definitiva con tal comentario, no es de extrañar que los artistas se sintiesen algo más que criticados, y por esta razón se publicó cuatro días después de la aparición de la crítica de Rafael Alfaro, la Segunda Carta abierta del Grupo Parpalló, en la que trasladarían su más absoluto descontento por unos comentarios que consideraban más injuriosos que críticos: "Hemos leído en el periódico de su dirección un comentario sobre la exposición que presentamos en nuestro Ateneo Mercantil. En dicho comentario se nos injuria tachándonos de bordear lo patológico y de insensatez. No hay que confundir una crítica con un insulto, y el señor "Rafael» lo ha confundido. En términos generales, su actitud no debe merecer comentario alguno. Ahora bien, en las líneas que firma el señor "Rafael» hay varias afirmaciones particularmente dignas de ser destacadas..." ${ }_{41}$

Estas afirmaciones, que posteriormente enumeran, justifican la gratuidad de algunos de sus comentarios; en primer lugar el cuestionamiento que hace de la buena fe de los pintores apenas visualizando algunas de sus obras, como los mismos artistas dicen: "Para saber de la buena o mala fe, es necesario penetrar en la conciencia de cada uno en ocasiones se nos conoce por las obras, se nos trasluce, incluso a pesar nuestro. Sin embargo bien pudiera ocurrir que no entendiéramos los propósitos de las obras y actos ajenos por muy claros que parezcan". ${ }^{42}$

Seguidamente dan ejemplaridad reseñando que pese a sus palabras seguirán creyendo que el cronista escribe guiado por los más nobles impulsos. En otro de los puntos constatan por medio de una breve reseña la existente tradición de la Escuela Valenciana a lo largo de la

40 AGUILERA CERNI, Vicente. "Vicente Castellano", en cat. exp. Exposición Vicente Castellano, Diputación Provincial de Valencia, Valencia, 1956.

41 GRUPO PARPALLÓ. “Segunda carta abierta del «Grupo Parpalló»”, Jornada, Valencia, 8 diciembre 1956, pág. 6. 42 Ídem. historia, principalmente desde el s XIV, que Alfaro pone en duda. Y por último, en un tercer punto, el grupo hace una defensa de todos los artistas que en la crítica aparecen personalmente atacados como es el caso del más joven de sus miembros Ribera Berenguer, cuyos paisajes fueron calificados como "envilecidos» y "payasada" y para su defensa ponen de manifiesto la valía del pintor por los méritos recientemente cosechados. Y finalmente la carta hace referencia al menosprecio de las obras de Castellano y de Montesa simplemente por la elaboración técnica de las mismas, que el Grupo Parpalló defiende de la siguiente manera: "Negar el valor plástico de un "collage» - caso de Castellano - es negar la misma pintura, que técnicamente no es sino un "collage" pues en principio se puede pintar con cualquier cosa que se pegue (esto ya lo dijo Leonardo).”43

$\mathrm{Y}$ con estas justificadas líneas defenderían su actividad como el más noble de los ejercicios artísticos, e independientemente de lo despectivo que pudiese llegar a ser, en el caso de Castellano, no tuvo mayor trascendencia a juzgar por los collages que volviese a presentar en exposiciones posteriores. El verdadero problema se presentaba cuando se sometía a juicio la propia práctica artística, exclusivamente por su resolución procedimental o sus resultados formales. Con el consecuente peligro que en una sociedad adormilada sería fácilmente generalizable una idea de este tipo y acabaría cuestionando la veracidad de los nuevos convencimientos plásticos.

Después de esta primera exposición con el Grupo Parpalló, Castellano regresó para instalarse definitivamente en el número 13 de la rue Rollin, en pleno Barrio Latino de la capital francesa. Desde París, Castellano trabajó independientemente, pero manteniendo una relación constante con la actividad del grupo, tanto a las exposiciones como a las actividades organizadas en torno a la revista Arte Vivo, cuyo primer número vio la luz en marzo de 1957. Arte Vivo fue elaborada por un escaso número de colaboradores que se encontraban coordinados por Vicente Aguilera Cerni y su financiación se hacía posible gracias al pago de cuotas periódicas de todos los miembros del grupo. En sus páginas, se podían ver noticias y convocatorias, y en sus escritos y artículos se intentaba generar un marco cultural, artístico y estético.

43 Ídem. 
La segunda exposición que el grupo realizó se pudo ver del 8 al 17 de mayo en el "Cercle Maillol" del Instituto Francés de Barcelona, donde el Grupo Parpalló se presentaba por primera vez. No todos los miembros presentaron obras; estuvieron: Vicente Aguilera, José Marcelo Benedito, Juan Genovés, Manolo Gil, Jacinta Gil Roncalés, Joaquín Michavila, Salvador Montesa, Nassio Bayarri, Vicente Pastor Pla, Francisco Pérez Pizarro, Juan de Ribera Berenguer y Vicente Castellano. El número de obras que se expusieron fue mucho menor, llegando a un total de diecinueve obras y entre ellas varios collages de Castellano, que sistematizaban su firme convencimiento con esta técnica artística.

La crítica aparecida en la revista Destino sobre esta segunda muestra apreció a los artistas como "adheridos en cuerpo y alma a las doctrinas del actualismo, con mayor o menor retraso, claro está, y con mayor o menor agudeza intelectual y sensitiva". ${ }^{44}$ Posteriormente hizo un recorrido por las obras presentadas, entre ellas los collages de Castellano. De estas palabras también podemos deducir que en general existía una notable percepción de que algo empezaba a ponerse en movimiento, de que el grupo generaba un dinamismo que agitaba el panorama artístico.

En el caso de Castellano esta "agitación" fue causada por los collages. El artista encontró en este procedimeinto una gran versatilidad que le permitió trasladar los planteamientos que ya aplicaba en sus obras pictóricas. Los papeles y cartulinas, así como otros cartones industriales reciclados, pasaron a ser las grafias de su lenguaje, donde color y forma conjugaron los vocablos de su expresión plástica. El ágil manejo de los recortes de papel para la elaboración de estos collages, le condujó a ricos y productivos ejercicios compositivos llenos de sugerentes combinaciones estructurales.

La $3^{\text {a }}$ exposición del grupo se celebró del 14 al 30 de junio de 1957, en el Palacio de la Generalidad de Valencia. Para dicha muestra se editó un pequeño tríptico desplegable donde aparecen los nombres de los artistas que concurrieron: Vicente Castellano, Albalat, Benedito, Estellés, Esteve Edo, Genovés, Manolo Gil, Jacinta Gil, Gimeno, Martínez Peris, Michavila,

44 CIRUELO, Pedro. "Grupo Parpalló", Destino n 1033, Barcelona, 25 mayo 1957, pág. 41.

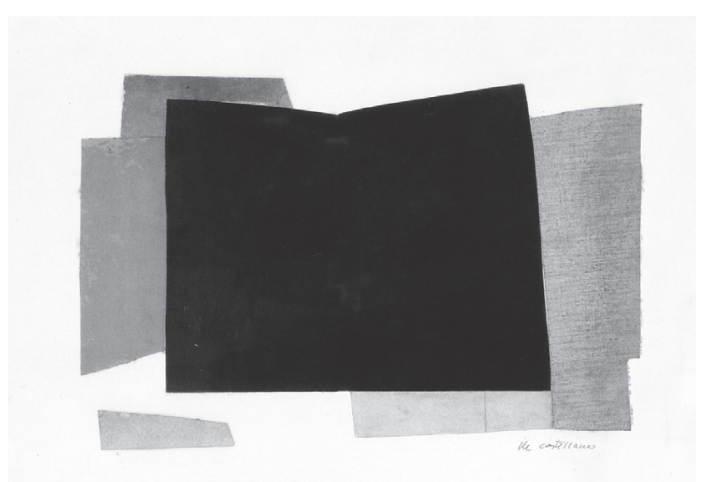

Figura 8: Vicente Castellano, Estructuras, Collage, 1957/58, $32 \times 49 \mathrm{cms}$.

Montesa, Nassio, Pastor Pla, Pérez Pizarro, Ribera Berenguer, Soler Boix y Soria.

Esta muestra fue percibida, según Manolo Gil, como "de gran interés para el ambiente artístico de Valencia ya que en su mayoría es la tendencia abstracta la que domina" y de modo particular hizo una apreciación de las obras expuestas por Castellano: "Vicente Castellano con sus collages se muestra más original que afortunado. Al situarse en un plano experimental $\tan$ valiente tiene el riesgo de la equivocación, cosa que naturalmente es siempre más fecunda y digna que el miedo a sufrirla". ${ }^{45}$ Palabras que van en sintonía con las que ya publicase en la crítica interna del primer número de Arte $\mathrm{Vi}$ $v o .{ }^{46}$ En ella manifestaba la necesidad de la experimentación en el arte -asumiendo sus inherentes consecuencias- frente al academicismo.

Manolo Gil fue uno de los artistas y teóricos más activos en la revista Arte Vivo, editada por el colectivo. Sin embargo, Gil falleció prematuramente en agosto de 1957, siendo su última participación en la segunda entrega. Tras la consternación por su inesperada muerte, el grupo tuvo unos meses de inactividad hasta diciembre de 1957 cuando se publicó la tercera entrega de Arte Vivo.

En esta última entrega, el grupo parece asimilar -o al menos el autor de el editorialla naturaleza con la que nació y apuestan en positivo por la riqueza que produce el debate abierto. El colectivo entiende que en lo expe-

\footnotetext{
45 RAMÍREZ PÉREZ, Pablo (comis.). Grupo Parpalló: 1956-1961 50é aniversari. Opus. cit. pág. 24.

46 GIL, Manolo. "Crítica interna: Construcciones plásticas de Salvador Montesa. "Collages» de Castellano" Arte Vivo, $n^{\circ}$ 1, Valencia, marzo 1957, sin paginación.
} 
rimental del arte, se ha encontrado a lo largo de la historia contemporánea un rico capital artístico y cultural, que desarrollado y destilado, ha derivado en todos los campos artísticos, gestándose así una renovación muy efectiva no sólo en el arte plástico, sino en el resto de las disciplinas afines.

En lo referente a la actividad expositiva, la última muestra se tituló Grupo Parpalló. Homenaje a Manolo Gil y se celebró entre los días 14 y 25 de enero de 1958 en la Sala del Prado del Ateneo de Madrid, donde se colgaron obras de Albalat, Genovés, Jacinta Gil, Michavila, Monjalés, Montesa, Pastor Pla, Pérez Pizarro, Soria, Castellano y del homenajeado Manolo Gil. La muestra dejó ver un nutrido número obras y la crítica volvió hacerse eco de la misma y apreció: "Los del Parpalló tienen talento, dignidad, escasa petulancia, y trabajan en un ambiente en el que no deben hallarse muy acompañados.... $\mathrm{Su}$ dignidad está también en sus obras. Me complace subrayar su gestión de los paisajes de Monjalés, el vigor de Jacinta Gil, el carácter de Albalat y otras calidades en las obras de Pastor Pla, Pérez Pizarro, Castellano y Michavila”. ${ }^{47}$

Pese a todas las opiniones surgidas de las exposiciones, una vez más parece echarse en falta algo que no termina de fraguar. Quizá lo que algunos miembros del colectivo, como el propio Aguilera Cerni, reiteradamente vienen advirtiendo, la carencia de unidad o de proyecto común. Falta que también perciben los espectadores y recogen las críticas de arte, que en su mayoría acaban apreciando el carácter indeterminado del grupo. "No quiero con esto, y el comentario precedente lo abona, hacer crítica negativa, porque entre otras razones siempre he acogido con la máxima simpatía toda tentativa...." ${ }^{48}$ Decía un artículo de la revista Arriba sobre la cuarta exposición.

Es suficiente este fragmento recogido de la prensa para entender que el proyecto inicial del Grupo Parpalló parece quedar en un mero manifiesto de intenciones, sin embargo el propio Pablo Ramírez igualmente reafirma esta idea: "Esta manifiesta disparidad estilística y de nivel que caracteriza los resultados artísticos canalizados a través de las primeras exposiciones or-

47 ANÓNIMO. "Grupo Parpalló", Ya, Madrid, 24 enero 1958, pág. 6.

48 FIGUEROLA-FERRETTI, L. "Coyuntura de la pintura actual. Grupo Parpalló exposición en el ateneo”, Arriba, Madrid, 18 enero 1958, pág. 17.

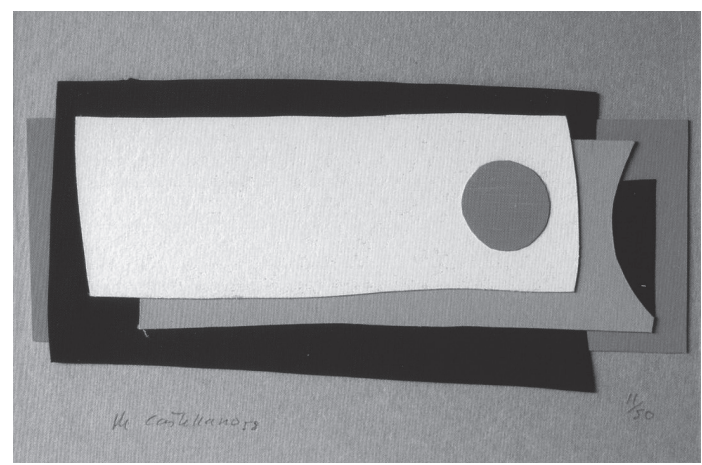

Figura 9: Vicente Castellano, Serigrafía Collage, Collage, 1958, 28 x $20 \mathrm{cms}$.

ganizadas por el Grupo Parpalló, demuestra que la primera etapa del colectivo valenciano, es externamente una etapa fallida, con insolubles problemas de coordinación física y de cohesión estética, e inevitablemente abocada a la crisis, aunque desde el punto de vista interno no deja de ser una etapa preparatoria, que resultó enormemente útil, si se tiene en cuenta la posterior renovación, algo así como un ensayo general". ${ }^{9}$

Esta cuarta exposición celebrada en enero de 1958, será la última en la que participó Castellano, que poco a poco sufrirá un progresivo distanciamiento del grupo. Por esta razón, esta fecha se puede entender como el momento que causa baja en el colectivo, pero bien es cierto, que pese a no participar en la quinta y última exposición de esta primera etapa, siendo "ajeno" a la crisis del grupo entre los meses de agosto y diciembre de este mismo año, y no concurriendo a la posterior renovación que dio lugar a la segunda etapa, no puede decirse legítimamente que causase baja. Tal y como evidencian las listas de miembros en las páginas de sumario de las revistas Arte Vivo, donde aparece su nombre en todos los números publicados, hasta la revista $\mathrm{n}^{\circ} 3$ de la segunda época $^{50}$ que viese la luz en mayo de 1959.

Por último podemos concluir que la aportación del Parpalló pudo resultar más o menos significativa en esta primera etapa del grupo, pero ciertamente, puso unas sólidas bases sobre un panorama yermo, en el que forjó los cimientos de una renovación que posteriormente se desarrollaría. Del mismo modo que sucedió

\footnotetext{
49 RAMÍREZ PÉREZ, Pablo (comis.). Grupo Parpalló: 1956-1961. Opus. cit. pág. 33.

50 RAMÍREZ PÉREZ, Pablo (comis.). Grupo Parpalló:
} 1956-1961 50é aniversari. Opus. cit. pág. 44. 


\begin{tabular}{|c|c|c|l|}
\hline exposiciones & año & días - mes & \multicolumn{1}{|c|}{ lugar } \\
\hline $1^{1}$ exposición & 1956 & $1-11$ diciembre & Ateneo Mercantill. Valencia \\
\hline $2^{\mathrm{a}}$ exposición & 1957 & $8-17$ mayo & $\begin{array}{l}\text { Cercle Maillol. Institut Français de } \\
\text { Barcelone. Barcelona }\end{array}$ \\
\hline $3^{\mathrm{a}}$ exposición & 1957 & $14-30$ junio & Palacio de la Generalidad. Valencia \\
\hline $4^{\mathrm{a}}$ exposición & 1958 & $14-25$ enero & Sala del Prado del Ateneo. Madrid \\
\hline
\end{tabular}

Figura 10: Participación de Vicente Castellano en las exposicione del grupo Parpalló.

años antes con el grupo Los Siete, cuando Castellano junto a sus compañeros de San Carlos buscaron nuevos cauces para canalizar sus inquietudes artísticas, alejándose del tradicionalismo y entendiendo la plástica como una actividad viva y evolutiva a través del tiempo.

\section{Conclusión}

Al estudiar estos primeros años de la trayectoria artística de Vicente Castellano y su participación en los grupos valencianos Los Siete y Parpalló, se evidencia, ante todo, el firme compromiso por parte de los artistas valencianos para la resurrección del panorama cultural español tras la posguerra y particularmente, el interés de Castellano por la renovación pictórica más allá del academicismo imperante.

Igualmente resulta ilustrativo el análisis del contexto en el que se desenvolvió el artista, para la comprensión de aquella realidad dentro de la cual discurrió su hacer plástico. Así como el funcionamiento de estos grupos de los que fuese miembro fundador e integrante, Los Siete y Parpalló. Sin lugar a duda, estos colectivos fueron actores de gran importancia para la re- novación de los ideales estéticos predominantes, y sobre todo, importantes actores para la canalización de las inquietudes de los jóvenes artistas valencianos de los años cincuenta. Resulta esclarecedor estudiar la participación de Castellano en estos colectivos y la dimensión e influencia que pudieron ejercer tanto en esta renovación "postimpresionista" que en Valencia fue heredera directa de los influjos Sorollistas, como el soporte que dieron de una forma muy especial a los artistas noveles con claros postulados antiacademicistas. Todo ello es vital para entender cómo y de qué manera llegó Castellano a desarrollar su obra pictórica.

Si en las trayectorias de todos los artistas existen momentos de especial trascendencia para el desarrollo de sus poéticas, sin duda, estos años serán esenciales para entender la aportación de Vicente Castellano a la pintura. Su participación en Los Siete coincidente con su estancia en la Escuela de Bellas Artes de San Carlos ya nos muestra como su pintura poseía un "trasfondo liberador". Sus escenas religiosas de carácter figurativo patentan mediante el formalismo de sus personajes un retrato psicológico que trasciende lo meramente plástico. Sin embargo será su adhesión al grupo Parpalló la que ayude más a la difusión de sus primeras obras parisinas que recogen ya los influjos de la vanguardia europea, ligando así, influencias históricas y planteamientos contemporáneos.

En definitiva una obra que supo trascender el academicismo para encontrar en París como bien dice Blasco Carrascosa "la fecunda experiencia de la conexión con el arte de su tiempo", ${ }^{51}$ generando así, una de las propuestas plásticas más válidas e interesantes de la segunda mitad del s. XX en España. 